\title{
An Evaluation of the Reaching Every District (RED) to Reach Every Child (REC) Immunisation Strategy in Mberengwa District, Midlands Province 2007-2010
}

\author{
Muchekeza $\mathrm{M}^{1^{\star}}$, Chimusoro $\mathrm{A}^{2}$, Nomagugu Ncube ${ }^{1}$ and Kufakwanguzvarova W Pomerai ${ }^{2}$ \\ ${ }^{1}$ Department of Community Medicine, University of Zimbabwe, Zimbabwe \\ ${ }^{2}$ Provincial Medical Director, Midlands province, Ministry of Health and Child Welfare, Harare, Zimbabwe \\ *Corresponding author: Muchekeza M, Department of Community Medicine, University of Zimbabwe, Zimbabwe, Tel: 263-4-303211; E-mail: \\ marymuchek@yahoo.com or marymuchie@gmail.com
}

Received date: 10 Feb 2014; Accepted date: 21 May 2014; Published date: 24 May 2014

Copyright: (c) 2014 Muchekeza M, et al. This is an open-access article distributed under the terms of the Creative Commons Attribution License, which permits unrestricted use, distribution, and reproduction in any medium, provided the original author and source are credited.

\begin{abstract}
Introduction: The immunisation program for Mberengwa district has been experiencing a decline in coverage and high dropout rates despite it having adopted the Reaching Every District strategy in 2004 . This study investigates reasons for this program failure.

Methods and Materials: The Logic Model Conceptual Framework was used to evaluate the program. Data were collected using questionnaires from health workers, key informants and a separate questionnaire used to collect data from mothers of children under five years old. Focus group discussions were conducted with women in the community. A checklist was used to assess program resource availability. Data were analysed using EPI info statistical software. Qualitative data were analysed thematically

Results: Forty six health workers and 56 mothers were interviewed. Ten health workers had been trained in Reaching Every District. Less than half knew the tool that is used to monitor program progress. None of the health centres had zoned catchment area maps for offering the different EPI services. Program resources were reported to be inadequate. None of the facilities were conducting regular EPI meetings with the community. Main barriers to immunisation were religious objectors, unavailability of vaccines and unavailability of outreach services

Discussion: Resources put into the program were inadequate. Health workers were not conversant with the operations of the strategy. Community involvement in the program was poor .Efforts to improve program performance should be aimed at training health workers in Reaching Every District, revitalising strong links with the community and re-establishing Expanded Program on Immunisation outreach services.
\end{abstract}

Keywords: Reaching every district; Immunisation; Mberengwa; Logic model framework

\section{Introduction}

The Expanded Programme on Immunisation (EPI) was launched in 1974 by the World Health Organisation (WHO) in order to reduce childhood morbidity and mortality burden due to vaccine preventable diseases $[1,2]$.

During the late 1980s and early 1990s immunisation coverage in the African Region increased steadily as countries and international partners intensified efforts to meet Universal Childhood Immunisation (UCI) goals [3]. By 2000 however the number of unimmunised children was alarming, leading to the establishment of the Global Alliance for Vaccines and Immunization (GAVI) [4]. The GAVI partners then recommended the Reaching Every District (RED) strategy to accelerate improvement in immunisation coverage [5,6].

The strategy has five main operational components which are:

Re-establishing outreach immunisation for the under-served populations.
Regular supportive supervision including onsite training of service providers by supervisors

Strengthening links between community and health services.

Monitoring immunisation programs for action.

Planning and better management of resources [7]

The RED approach was introduced in Zimbabwe in 2004 with support from the World Health Organisation with Mberengwa district being one of first to implement the strategy.

The immunisation coverage for Mberengwa district for measles, oral polio vaccine and pentavalent vaccine for the years 2007-2010 have failed to reach the expected immunisation coverage targets which are $85 \%, 90 \%$ and $95 \%$ respectively. This study investigates reasons for immunisation program failure in the district.

\section{Materials and Methods}

A process and outcome evaluation study was carried out using the logic conceptual framework. We assessed the in-puts which were injected into the program, the processes carried out and the out puts 
Citation: Muchekeza M, Chimusoro A, Ncube N, Pomerai KW (2014) An Evaluation of the Reaching Every District (RED) to Reach Every Child (REC) Immunisation Strategy in Mberengwa District, Midlands Province 2007-2010. J Vaccines Vaccin 5: 1000235. doi: $10.4172 / 2157-7560.1000235$

Page 2 of 5

and outcomes of the program in Mberengwa district of Midlands Province.

We interviewed nurses and nurse aides manning the health facilities and participating in the EPI programme. The DNO (District Nursing Officer), CHN (Community Health Nurse), DHIO (District Health Information Officer) and District EPI focal person (a nurse nominated by the DNO) were key informants.

Fifteen $(>50 \%)$ of the twenty nine clinics and three of the five hospitals were randomly selected. Focus group discussions with groups of 8-10 women found at various gatherings in the community were conducted to identify bottlenecks to immunisation in the community. Mothers of Under $5 \mathrm{~s}$ found at all health centres were also randomly selected and interviewed.

An observational checklist was used to check for availability of a catchment area map, register for all children under 1year, EPI refrigerator, EPI stationary.

Interviewer administered questionnaires were used to interview nurses, nurse aides and mothers of under $5 \mathrm{~s}$ to assess knowledge on the RED approach and to identify possible barriers to immunisation.

EPI-info version 3.5.1 was used to generate frequencies, proportions and means of variables while qualitative data was analyzed manually

Permission to carry out the study was sought from the relevant authorities. Verbal consent was sought from the health workers while a written informed consent was sought from members of the community/mothers of under-fives.

\section{Results}

Forty six (46) health workers and fifty six (56) mothers of under $5 \mathrm{~s}$ were interviewed while ten focus group discussions were carried out with groups of 8-10 women accessed at various gatherings in the community. The majority of health workers interviewed $(71.7 \%)$ were female and being mostly (54.3\%) primary care nurses. Their median years in service were 5 years and their median age was 37 years $(Q=32$; $\mathrm{Q} 3=41$ ).

Eighty two percent of mothers of under 5s interviewed (82.1\%) were married. Most mothers were Christian and belonged to the orthodox churches. Fifty seven percent (57.2\%) of all mothers interviewed had attained secondary level education. Their mean age was 27.5 years $(\mathrm{SD}=5.5)$.

A total of 30 health workers were trained in RED at its inception in the district in 2004. However 12/30 was still available in the district in 2010.

Ten $(21.7 \%)$ health workers interviewed had received previous training on the Reaching Every District approach. Most health workers reported correctly on the objectives of the RED approach. Almost 90\% of all health workers did not know the correct expected targeted coverage for all the antigens used in the RED strategy.

Forty three percent (43.5\%) of all health workers reported correctly on the main indicator used for monitoring EPI coverage at district and rural health centre level.

The resources received for implementing RED were inadequate throughout 2007 to 2010 as shown in Table 1.

Fifteen out of the eighteen health facilities did not have the EPI policy documents available. Fifty six percent (56.5\%) of all health workers reported having experienced vaccine stock outs in the past 6 months for periods ranging from a minimum of one week to maximum of three months.

\begin{tabular}{|l|l|l|l|l|l|l|l|l|l|}
\hline Item & \multicolumn{2}{|l}{2007} & \multicolumn{2}{l|}{2008} & \multicolumn{2}{l|}{2009} \\
\hline & Req & Aloc & \%Aloc & $\begin{array}{l}\text { Re } \\
\text { q }\end{array}$ & Aloc & \% Aloc & $\begin{array}{l}\text { Re } \\
\text { q }\end{array}$ & Aloc & \%Aloc \\
\hline $\begin{array}{l}\text { EPI } \\
\text { fridges }\end{array}$ & 40 & 25 & 62 & 20 & 5 & 25 & 15 & 5 & 33 \\
\hline $\begin{array}{l}\text { Vaccine } \\
\text { Carriers }\end{array}$ & 70 & 30 & 43 & 40 & 10 & 25 & 30 & 10 & 33 \\
\hline $\begin{array}{l}\text { Full gas } \\
\text { cylinders }\end{array}$ & 48 & 30 & 63 & 14 & 5 & 36 & 9 & 4 & 44 \\
\hline
\end{tabular}

Table 1: Inputs received in Mberengwa district for implementation of RED (2007-2009). Req- required; Aloc- allocated; \% Aloc- percentage allocated.

Only 2/18 health centres reported having adequate EPI stationary in 2007 and 2008 and this increased to 4 health centres in 2009.

The most commonly reported antigens for having been out of stock in the district in the previous 6 months were pentavalent vaccine, BCG and oral polio vaccine.

All key informants reported that they had received vaccine carriers, icepacks, thermometers, vaccines, needles and syringes in the year 2009 for the implementation of the program and had not received any funds or EPI stationary. The district received one vehicle from UNICEF in the period under review.

Key informants reported that most RED activities for the period of 2007-2009 were not planned for and hence not conducted due to unavailability of resources such as transport and fuel. All key informants reported that only a few advocacy and social mobilization meetings had been held in the period under review but could not enumerate exact numbers of such meetings that were held. Minutes for these meetings were not available. District EPI outreach points were neither identified nor fully functional and training of health workers had not been completed.

Forty five (97.8\%) health workers reported that District EPI supervisors do make supportive supervisory visits to their health centres. Thirty two $(69.6 \%)$ health workers reported the supervisory visits as being done erratically and this was supported by records that were available in the supervisory books.

Twenty seven (58.7\%) of all health workers reported having held advocacy meetings with community leaders in the past 1 year. Thirty (65.2\%) health workers reported having held social mobilization meetings with different target groups in the community in the past 1 year however there were no minutes available for the researcher to see.

Most (70.7\%) health workers reported the REC program as useful in increasing the EPI coverage using the Pentavalent 3 as a proxy indicator. Only $56.5 \%$ however reported correctly on the tool which is used to monitor progress of the EPI program.

All(18) health centres had catchment area maps and immunisation registers for the children under 1 year of age in their catchment area however $4 / 18$ of them had registers which were not updated. None of the catchment area maps were classified into the different zones as is required for RED implementation. Only 6/18 health centres had EPI 
micro plans for the year 2010.None of the centres had updated quarterly EPI graphs or outreach plans.

A total of 56 mothers of under-fives were interviewed. Most (98.2\%) mothers of under $5 \mathrm{~s}$ found at the health facilities reported correctly on vaccine preventable diseases (VPDs). Sixty four percent $(64.3 \%)$ of them also stayed less than or equal to $8 \mathrm{~km}$ away from the health centre. Twenty five percent $(25 \%)$ of the mothers had received health education on immunization in the previous 6 months. A majority (98.2\%) reported that they had support from family members to take children for immunization.

Most women reported that immunizations were very beneficial in preventing childhood illnesses as was reported in 8/10 FGDs. Reports from $7 / 10$ FGDs indicated that the community was willing to support the immunisation program. The most common reasons reported from FGDs for some children not being immunized were religious objection, clinics being too far and vaccine unavailability at clinics.

The most commonly reported barriers to immunization that were reported included religious objectors to immunizations, health centres being too far from some populations, lack of previous health education on EPI among community members and waiting too long for EPI services at the health centres as shown in Table 2. The district did not apply the different strategies used to reach the populations in the different zones of the catchment area due to lack of resources for conducting outreach EPI sessions as reported by both health workers and key informants.

\begin{tabular}{|l|l|l|}
\hline Factor & $\begin{array}{l}\text { Number of } \\
\text { mothers } \\
\text { reporting factor } \\
\text { (n= 56) }\end{array}$ & \% \\
\hline $\begin{array}{l}\text { Distance to health centre } \\
>8 \mathrm{~km}\end{array}$ & 20 & 40 \\
\hline $\begin{array}{l}\text { Lack of satisfaction with EPI services because } \\
\text { of: }\end{array}$ & 17 & 30.4 \\
$\begin{array}{l}\text { Waiting too long } \\
\text { Bad health worker attitudes } \\
\text { Previous EPI sessions cancelled }\end{array}$ & 8 & 16.1 \\
\hline Lack of previous health education on EPI & 42 & 75 \\
\hline Religious objectors & 36 & 64.3 \\
\hline
\end{tabular}

Table 2: Barriers to immunization in Mberengwa district, 2010

The district has not met the EPI targets for all antigens in the period 2007-2010. The dropout rates for all antigens have remained above $12 \%$ throughout the period under review as shown in Figure 1.

\section{Discussion}

Health workers in Mberengwa district were not effectively implementing the RED strategy to increase immunization coverage and reduce high dropout rates. Operationalization of the five RED components is very important as it assists health staff in improving EPI utilization by the community thereby increasing EPI coverage.

Health workers' knowledge on objectives and strategies used to reach different populations zones of the catchment area was high. Their knowledge on the expected operations of the RED approach was however very low as evidenced by failure to classify the catchment area maps into zones at all institutions that were visited. This failure to classify populations into the different zones meant that the different strategies were not being implemented to reach these populations thereby leaving a lot of children not being reached by the EPI services.

The majority of health care providers interviewed had not been trained in RED and on job training at health facilities was not being done within the district. This was probably the main reason why most of them did not know the expected operations of the RED strategy. Without ongoing training for new staff, or regular refresher training for existing staff, high levels of staff turnover leave the EPI programme vulnerable to poor performance.



Figure 1: Percentage drop out rates for different antigens for period 2007 - 1stQuarter 2010, Mberengwa district.

Conducting EPI review meetings and community advocacy meetings assists in sharing information and can significantly improve the immunization coverage. In Mberengwa district these meetings were not being held at health facility level and this may have contributed to the low EPI coverage and high dropout rates. These meetings provide a strong link between the community and health care providers and therefore play a key role in improving EPI service utilization. This is supported by findings from an evaluation of the RED strategy in the African region in 2007. In this evaluation community involvement through regular EPI meetings and use of community volunteers for defaulter tracking and community education was noted to improve immunisation service utilization [9].

Active involvement of community volunteers has been reported to be vital in increasing immunization demand particularly for outreach in rural areas in a study done Ghana $[10,11]$ in 2005. The willingness by community members in Mberengwa district to support the EPI program provides a strong basis for program revitalization and strengthening by tapping this readily available human resource for use to improve service utilization.

Linking health facilities with communities has been proven to be an effective strategy in improving immunization coverage especially in developing countries. In Parsa district, Nepal linking health facilities with communities through village development committee orientation in 2004 was found to improve immunization coverage and reduce dropout rate drastically [12].

Appropriate planning and budgeting are important components of immunization programs. In Mberengwa district however the RED micro plans were only available at the district level and at 6/18 visited health centres. None of the health facilities had outreach plans in place. All health facilities reported not having received financial 
support, fuel or some form of transport for outreach sessions. Proper planning helps direct program activities and orients workers towards achievement of intended program goals.

Supportive supervisory visits are required for regular detailed follow up with EPI health care providers to ensure tasks are being implemented correctly. The majority of health workers interviewed at the various health facilities visited reported that these visits were not done on an unscheduled basis depending on whether district supervisors found transport to their health centres. In Mberengwa unavailability of resources for supervision was cited as a challenge at managerial level. Similar findings were reported in an evaluation that was done in Sierra Leone in 2005 where lack of transport was reported to be a challenge as it disrupted supportive supervisory visit schedules, distribution of vaccines and EPI materials [9].

Regular supportive supervisory visits have also been noted in other studies to motivate staff and helped encourage health workers to integrate EPI services with other services [13].

Less than half of all health workers interviewed reported correctly on targets for all EPI targets. This meant that even though health workers in the district were calculating EPI coverage and dropout rates this data may not have been used for any public health action. Without accurate interpretation of EPI data no monitoring and evaluation of the EPI program was done and subsequently no actions were taken to improve EPI coverage and service utilisation.

Almost half of all health workers did not know the tool which is used to monitor EPI progress. The low use of data by health workers was identified as one of the system related barriers to the attainment of high EPI coverage by the Norwegian Agency for development cooperation in 2004 after coordinating a GAVI work plan area consultation with country representatives seeking to explore ways to address system- wide barriers to immunization [14].

The uptake of immunisation services in Mberengwa district was poor as indicated by the high dropout rate across the different years evaluated for the different antigens. This could be attributed to the fact that all health facilities in Mberengwa have minimal involvement of the communities in EPI/RED activities. Moreover health institutions in Mberengwa district were not conducting outreach sessions. Poor social mobilization and insufficient community participation were two of the reasons identified as major contributing factors for poor coverage and high dropout rates. A Knowledge, Attitude, and Practices survey in 1998 found that health workers were deficient in their understanding of immunization and that community participation in immunization services was low, despite the willingness of communities to fully support programs [10].

Services need to be linked with communities to enhance community appreciation, ownership and demand. Following an assessment to Reduce Drop Out rates in Côte d'Ivoire, Koua et al. observed a decline in overall routine EPI performance. Main causes of high dropout rates were reported to be stopping/irregular outreach or mobile immunization strategies, inadequate immunization schedules, inadequate follow-up of children immunized during fixed and outreach strategies and missed oppurtunities [15].

The REC program was reported by all key informants not to be achieving its objectives due to resource unavailability. Adequate resource availability is very important for the EPI program to achieve its targets. Lack of human resources and under financing of health care was noted to be the major barriers in a study done in Mongolia to determine factors associated with low immunization coverage [16].

Most of the mothers reported being supported by family members in bringing their children for immunization and most were the decision makers themselves in terms of whether or not to take children for immunization. This could however be due to the fact that all the mothers interviewed in this study were found at the health centres and hence their behaviour was already positively skewed towards seeking health care for themselves and their children. These findings are however contrary to those from other studies where the male partner's dominance or lack of support and prejudice has been reported to affect women and children's access to health. The general lower levels of health related knowledge and awareness among poor and marginalized groups of women has also been reported to result in low demand for health care services $[17,18]$.

The most common barriers to utilization of immunization services that were reported by members of the community in Mberengwa district included waiting too long for services at the health centres, bad health worker attitudes towards patients, religious objection to immunizations, unavailability of some vaccines at the health centres and too long distances to the health centres. Waiting too long for health services and bad health workers attitudes towards patients could have been caused by low staffing levels at the health centres resulting in high work related pressure and low morale among health workers. The existence of religious objectors to immunisation posed as a threat to the achievement of the EPI program targets in Mberengwa district [19].

All RED components were not being implemented fully to improve achievements of the immunization programme in Mberengwa district. The inputs injected into the EPI/RED program in the district during the period 2007- 2010 were inadequate. Program performance was therefore greatly undermined by poor resource availability. Less than a quarter of all EPI service providers were trained in the RED approach. As a result health workers' knowledge on the expected operations of the RED approach was very low. Processes such as zoning of the catchment area map, conducting outreach sessions, conducting EPI social mobilisation meetings and holding EPI advocacy meetings with community leaders were not being done as expected in the district. This resulted in poor community involvement in the EPI program in the district despite the community's willingness to support the program. Outputs realised by the program were poor. Community utilisation of the EPI services was threatened by the presence of religious objectors, EPI resource unavailability, unavailability of outreach programs, too long distances to health centres and poor links between the community and health care providers.

We recommend the district team to coordinate trainings on the RED approach, come up with plans to strengthen static EPI services, ensure adequate vaccines and other EPI resources are availed to all health centres, consider conducting regular local immunisation days for the district, to plan and conduct regular scheduled support and supervisory visits and to conduct regular advocacy and social mobilisation meetings on EPI in the district.

\section{References}

1. Kopano M (2009) Achieving the Millennium Development Goal to reduce under- five child mortality: A UNICEF Perspective.

2. Expanding immunisation coverage, 2010. 
Citation: Muchekeza M, Chimusoro A, Ncube N, Pomerai KW (2014) An Evaluation of the Reaching Every District (RED) to Reach Every Child (REC) Immunisation Strategy in Mberengwa District, Midlands Province 2007-2010. J Vaccines Vaccin 5: 1000235. doi: $10.4172 / 2157-7560.1000235$

Page 5 of 5

3. World Health Organisation (2009) State of the world's vaccines and immunisation, 3rd edition. UNICEF.

4. Wolfson LJ, Gasse F, Lee-Martin SP, Lydon P, Magan A, et al. (2008) Estimating the costs of achieving the WHO-UNICEF Global Immunization Vision and Strategy, 2006-2015. Bull World Health Organ 86: $27-39$.

5. WHO (2005) Immunisation against diseases of public health importance.

6. World Health Organisation (2005) Reaching Every District Strategy Implementation in the African Region, Evaluation Report.

7. World Health Organisation. Reaching Every District (RED): African Region Implementing RED.

8. Ministry of Health and Child Welfare (2005) Zimbabwe Expanded Program on Immunisation (ZEPI) Policy Document.

9. WHO/AFRO (2007) In-Depth Evaluation of the REACHING EVERY DISTRICT APPROACH in the African Region.

10. Ministry of Health (2003) Increasing immunisation coverage in Uganda The Community Problem Solving and Strategy Development Approach.

11. Diamenu S, Eshetu M (2005) Bringing Immunisation services closer to communities The RED experience in Ghana, WHO, Ghana.

12. Krishma SH, Siddiqi M (2004) Reaching Every Child for primary immunisation, an experience from Parsa District, Nepal.
13. Kaoma M, Mwale HF, Chirundu L (2004) Reaching Every District Strategy improves community participation in immunisation of children: Zambia's experience. APHA Scientific Session and Event Listing.

14. Global Alliance for Vaccine and Immunisation (GAVI) (2004) Alleviating system wide barriers to immunisation.

15. Koua A (2004) Reducing Drop Out rates in The Côte d'Ivoire Experience.

16. Enkhtuya B, Badamusuren T, Dondog N, Khandsuren L, Elbegtuya N, et al. (2009) Reaching Every District- development and testing of a health micro planning strategy for reaching difficult to reach populations in Mongolia. Rural Remote Health 9: 1045.

17. Cutts FT, Glik DC, Gordon A, Parker K, Diallo S, et al. (1990) Application of multiple methods to study the immunization programme in an urban area of Guinea. Bull World Health Organ 68: 769-776.

18. WHO/Western Pacific Region (2008) Barriers to access to child health care, reaching the poor, 2008.

19. Chadambuka A, Chimusoro A, Apollo T, Tshimanga M (2006) Assessing the Effectiveness of Immunisation Strategies in a District with Low Immunisation Coverage in Zimbabwe. 